\title{
STRENGTHENING SOCIAL IMMUNITY THROUGH COLLECTIVE RESPONSIBILITY: INDIA'S EXPERIENCE IN CHALLENGING THE UNCERTAINTY
}

\author{
Dr. Sasmita Patel ${ }^{1}$, Susanta Kumar Padhiary ${ }^{2}$ \\ ${ }^{1}$ Assistant Professor at Department of Social Work, Visva-Bharati (A Central University), \\ West-Bengal, India \\ ${ }^{2}$ Founder Director, Bhagidari Eco Innovations, Kendrapara, Odisha, India
}

Article DOI: https://doi.org/10.36713/epra9447

DOI No: 10.36713/epra9447

\begin{abstract}
Since the outbreak of COVID-19, the population across the world has been confronted with uncertainty and unpredictability. The world had never been contemplated such a far-reaching, more complex pandemic paradox. As agreed by several experts worldwide, fighting a battle with the COVID-19 pandemic is as complex as any World War. Before understanding its intensity, it created a wider geographical influence and emerged as a global challenge to communities' health and health care services, economy, politics, and psycho-social environment. It created a vast blockage for humans and society to progress. The pandemic drastically changed the emergency and humanitarian paradigm of disaster management in the nations, which demanded extraordinary actions from the government and communities. It necessitated scientific interventions with a multi-sectoral approach implicit in the social immune system. It was seen that there had been a significant role of collective efforts of the groups and communities that helped to strengthen social immunity.

The study is primarily based on secondary sources. The authors' observations have also been substantiated in analyzing the secondary data. It has tried to analyze the available literature obtained from various journal articles, books, newspapers, e-resources. They have tried to understand how social immune systems played a vital role in challenging the uncertainty borne by COVID- 19. The paper concludes with a reflection on the perspective of the proposed social immunity framework and its possible applications during an emergency, unlike the current pandemic, the significance and dimensions of social immunity, and understanding India's experience on social immunity initiatives during the COVID-19 crisis.
\end{abstract}

KEYWORDS:Social immunity, Collective responsibility, COVID-19, Crisis management, interdependence

\section{INTRODUCTION}

Coronavirus surfaced in China in late 2019, and after two months of inception, the COVID19 pandemic was depicted as a public health emergency of global concern by the World Health Organisation(WHO). It has brought the communities with a severe health crisis that exhausted the medical systems, engaged a considerable lot of economy and resources, and grabbed the full attention of civil society organizations in responding to the emergency. It is seen that the social implications of the pandemic are much more disastrous than that of its medical dimension. Thus, it required the social immune systems to be strengthened and used as a vital element in fighting against the virus. Working on social immunity to deal with the disease provides an integrated approach to understanding the dimensions of illness. It helps in understanding the kind of dynamics that works behind the infections. Therefore, strengthening social immunity itself is a challenging task. It is a collective effort of the group members that emerged from the cooperation of individual members in the group to combat the increased risk of disease spread that arises from sociality and group living (Cremer, S. et al.,2007).

Before discussing the social immune system, it is essential to understand 'immunity' and its great 
importance in our body and mind. 'Immunity' is derived from the Latin word 'immunise,' which means 'protected' that refers to the management of the social and biological (socio-biological) immune system. It plays a very crucial role in keeping us healthy. Napier (2013), stated "The relation between biological processes and social practices has given rise to sociobiology heavily defined through experimental, cause-and-effect theorizing, applying biology to society, culture, and individual action. Human behavior is largely understood as the outcome of biological processes, with individual autonomy and survival and social order and stability prioritized. It plays a very crucial and dynamic role in keeping us healthy". But in another way, 'social immune' always plays a dynamic role in contributing to positive mental well-being. According to Cremer, et al. (2007), "Social immunity is a term originally used to define the collective defense mechanisms practiced in eusocial insects (e.g., ants, bees, termites, and wasps) that result in avoidance, control, or elimination of infections. Again the author emphasizes collective effort for collective benefit. Cremer, et al. (2007) highlighted that "The symbol of these defense mechanisms is that single individuals cannot perform them efficiently. They require the collaboration of several individuals and are usually mounted for a collective benefit". It always influences our psycho-social behaviors based on interpersonal relationships and the degree of interdependence. Here, immunity is realized in the context of bodily protection and is highly internalized in socio-political and Environmental aspects. It creates an enabling environment to protect our community collectively from even the daily COVID19. It makes us realize that body immunity is entirely insufficient in the fight against unseen viruses; instead, the strength of socio-, political, and environmental factors are significant in determining individual immunity.

Below are the objectives of the present study.

\section{OBJECTIVES}

- To understand the importance of social immunity in addressing the current crisis of COVID-19.

- To study the dimensions of social immunity and its role in dealing with the pandemic.

- To critically analyze the collective role of communities in strengthening social immunity, especially in the Indian context regarding the current pandemic.

\section{METHODOLOGY}

The paper has primarily used secondary data collected from journal articles, newspapers, and several online sources. It has tried to understand the importance and dimensions of social immunity in addressing the current crisis of COVID-19. It has also critically analyzed the collective role of communities in strengthening social immunity, especially in the Indian context regarding the current pandemic. However, the study has also used the authors' experience and exposure on how the civil society and communities have been engaged in addressing the pandemic with their spirit. For a better understanding and reference, the authors have proposed a framework on Social Immunity. Based on the objectives, the paper thematically analyses and reflects upon the role of social immunity and the strength of collective responsibility in strengthening social immunity in challenging uncertainty caused by COVID-19.

\section{The Importance of Social Immunity in Addressing the COVID-19 Crisis \\ i. The COVID-19 as the Paradigm Shift}

The COVID-19 pandemic emerged as a paradigm shift for biomedical scientists and social analysts. Handling the situation has emerged as an interdisciplinary approach that necessitated a strategically oriented collaborative effort and created an ethical debate surrounding the social implication of health and health care. This emerging paradigm reinforced all in dealing with the situation with a broader perspective considering the bodily and social immune systems. It provided an opportunity for biomedical scientists to exercise their medical intervention, considering the dynamic characteristics of coronavirus and its contagiousness. In another way, it created an opportunity for social analysts to understand and work on the socio-economic and political implications of the pandemic. Thus, it needs interdisciplinary cooperation and coordination to determine care ethics. "In the collective care ethics is basically understood as the ethics of responsibility that ultimately manages the web of relationships and that connect everyone for the good of everyone (Kroeger-Mappes, J, 1994)". Careful management of each dimension of even a physical disease includes full engagement of social immunity. Dealing with COVID-19, people have registered a paradigm shift in comprehending and engaging the whole resources to deal with a global problem with our social immunity.

\section{ii. Significance of Social Immunity}

"Social immunity is significantly broader than the current use of the term (e.g., Cremer et al. 2007; Cremer and Sixt 2009; Wilson-Rich et al. 2009).In a landmark paper, social immunity" was first coined to describe the group-level immune function exhibited by social insects and group-living primates (Cremer et al., 2007). Specifically, it describes immune defenses that are mounted by a collective to benefit themselves and others (e.g., Cremer et al., 2007; Cremer and Sixt 2009; Wilson-Rich 
et al. 2009). The key idea is that individuals are better able to mount a defense than it is possible by acting collectively. In this same line, Cotter, S. C., and Kilner, R. M. (2010) said that "it is the collective nature of the immune response that puts the social into social immunity rather than the fact that it is being mounted for the benefit of others as well." Here mutuality, cooperation, trust, and social interdependence are the fundamental aspects of social immunity. It boosts the group members' mental efficiency and psychological relief in tackling the uncertainty, which has not been possible alone. The core value of interdependence plays a vital role in establishing the social immune system more strongly.

In human behavior and practices, the social immune system performs a vital role as a strong determinant that depends on the socioenvironmental factors. Social immunity is the outcome of the collectiveness of people in combating the possible risk of disease transmission that triggers in group living. According to Shultz et al. (2011), "living in large social groups offers several advantages." It reduces predation risk, abridges the care for offspring, and improves food foraging and food protection. Yet, it also has its disadvantage - it increases the risk for transmissible infections (McCallum et al., 2001).

We have also seen the same in the case of the coronavirus crisis. Cote and Poulin (1995) say, "Pathogens can spread more easily among members of groups that exhibit social contact, share food and move around in the same territory. Accordingly, social isolation is a common intervention that can contain infectious diseases by reducing transmission in humans and animals. Thus a restriction on movement bans on travel and public gathering (Hatchett et al., 2007; Markel et al., 2007), quarantine (Fraser et al., 2004; Tognotti, 2013), selective culling (Fèvre et al., 2006), school closures (Earn et al., 2012) have proven successful in containing epidemics. According to Cremer, S. et al. (2017), Group living has many benefits compared to a solitary lifestyle. Group living has both sides when we see it in the context of a pandemic like COVID-19, where the disease is highly contagious. But by strengthening collective responsibility, communities can fight with the pandemic being physically distant yet united in their efforts. Group living contributes to collective strength, which clears away all the blocks and strengthens social immunity to tackle unprecedented situations.

\section{Dimensions and Role of Social Immunity}

i. Social Immunity Leads to Social Resilience

Social immunity is one of the critical elements of social resilience, and it has a positive effect on lifelong health. It supports people to be more resilient to cope and challenge uncertainty. Therefore, everyone has an indispensable role in maintaining immunity in various ways, which could help in improving personal and socio-political resilience. Resilience is the process that permits individuals to adapt to adverse conditions and recover from them. It could be possible when interdependence and collectively performed adaptations will work together. The same is evident in the case of the current crisis; social immunity has significantly impacted reducing the bearing of infectious disease and improving our resilience.

During the pandemic, it is experienced that millions of people have lost their lives, and millions are directly or indirectly affected by the virus. As per Global data (WHO Coronavirus (COVID-19) Dashboard,14 January 2022 as of 6:03 pm C.E.T.), there have been $318,648,834$ confirmed cases of COVID-19, including 5,518,343 deaths. Though the human race has lost a lot in the pandemic, it has indirectly created an opportunistic situation for all to learn the basic life skills which are of the utmost importance in our lives to live healthy and secured. These actions range from physical distancing from others at the time of group gathering/ meeting, maintaining hygiene and sanitation, regular hand washing appropriately, using of max while outside, using alcohol-based sanitizers, taking balance and healthy foods, keeping the environment clean, practicing regular exercise, taking formal advice of the doctors, adhering to the State rule at the time of emergency, and to stay self-quarantine if affected, etc. These are the new lifestyles that are essentially required for all, and these collectively performed adaptation skills are the need of the hour for all. These are the best shreds of evidence of resilient strategies for combating the COVID-19 pandemic.

\section{ii. Higher Level of Social Trust Leads Social Immunity}

According to the World Happiness Report, the United Nations Sustainable Development Solutions Network (2020), "communities and nations with higher levels of social trust and connections are more resilient in the face of natural disasters and economic crises." Immune fitness is the human body's secret, and the social immune is the determinant of the human mind. Social immunity strengthens through our interpersonal relationships and a higher level of social trust. It provides an extra layer of mental support and boosts our health, even when isolated. Social connection and interpersonal relationships are crucial to health and happiness, even alone. A sense 
of being connected and trustworthy to someone connected are the psychological and social need needs that increase our interdependence and impact our mental health, physical health, and longevity. According to Brown, B. professor at the University of Houston Graduate College of Social Work(), "A deep sense of love and belonging is an irresistible need of all people. We are physically, cognitively, and spiritually wired to love, be loved, and belong. When those needs are unmet, we don't function as we were meant to. We break. We fall apart. We numb. We ache. We hurt others. We get sick." Seppälä, E. (2020) talks that "social trust is the foundation of social immunity, and it leads to mutually beneficial intersection (cooperative behavior) fight against the foreign elements. It is an indispensable requirement of society, and it works as a robust response to absorb shock during the crisis and maintain social tranquillity for gaining social immunity".

\section{iii. Social Immunity Leads in Minimising Morbidity and Mortality}

The immune system has a central role in many processes that may positively impact patients minimizing morbidity and mortality. Indeed, an individual's immune fitness depends on its likelihood of survival and its ability to transmit its genes into the next generation. "The World Health Organization (WHO) defines health as not just the absence of disease, but rather in the broad sense of physical, economic, emotional, and social well-being at an individual, family, and community level. Health is thus affected by individual risk factors and behaviors and a range of economic and social circumstances. These social elements of health-the circumstances in which people are born, grow up, live, work, and age-are shaped by various economic, social, and political policies and forces. These policies and forces - what the WHO describes as the social determinants of health inequities - in turn, regulate access to life chances and opportunities for health based on social markers of advantage and disadvantage such as race and ethnicity, class, and gender"(Geoffrey, R. and Swain, 2016-17).

\section{The Collective Role of Communities in Strengthening Social Immunity}

i. Factors Strengthening Social Immunity During the Crisis

Social immunity is a collective effort that emerges through collaborative health practices at the individual, family, and societal levels. It gives extra protection to the individual and provides selfawareness about healthy behaviors. The socioeconomic factors and the physical environment of the states are the necessary conditions that determine the quality of health services and their accessibility. It also impacts individual and social immunity. Along with these, knowledge, skill, and aspirations play as a survival strategy to fight against the unseen virus and become helpful to adopt healthy behavior and practices that helps tackle the disease. Also, it creates a circle of concern and influence, which becomes instrumental for minimizing human damage and boosting our social immunity against the virus. Thus, the socio-economic and physical environment is crucial in controlling our immune system. Social immunity (also termed collective immunity) describes the additional level of disease protection arising in social groups from collective disease defenses, performed either jointly or towards one another. These collective defenses complement the individual immunity of all group members and constitute an extra layer of protection at the group level, combining behavioural, physiological and organisational adaptations" (Meunier, J. 2015).

\section{ii. Social Immunity Initiatives: India's Experience}

\section{a. Social immunity initiatives among indigenous} people

Having a high level of social immunity backed by interdependence is a way of life of indigenous people. During the COVID-19 pandemic, it is seen that the solid social immunity made them resilient to the infection. In many parts of India, the tribals (indigenous communities) have developed their indigenous strategy to deal with the pandemic. They have taken their actions in many ways by using their traditional knowledge and practices such as preparing masks from plant leaves, sealing off their territories, voluntary isolations, taking traditional food as immunity boost up, and preventive measures. These inbuilt capacities have shown resilience by establishing, maintaining, and regulating an appropriate immune response against COVID-19. Likewise, many indigenous communities worldwide have adopted different innovative practices. The traditional leaders and local authorities in remote areas have also revived traditional approaches to build their social immunity to challenge the uncertainty backed by the virus. Their interdependence always creates a safeguard for them from the outside elements. There is some evidence found in different parts of the tribal districts of Odisha during the pandemic like the locals in farflung locations in tribal-infested Kandhamal district of Odisha have developed a creative method to prepare masks from plant leaves to save their families from infections (Sambad English Bureau, 28 March 2020). Parallelly, tribal communities in Chhattisgarh, Jharkhand, West Bengal, and many north-eastern states have taken indigenous measures to fight the pandemic. 


\section{b. Social Immunity initiatives Among Community Groups}

Community groups like S.H.G.s, youth groups, and resident welfare societies in urban areas have been instrumental in fighting the COVID-19 pandemic. They have played a pivotal role in tackling the situation in managing their families and adopting collective measures, assisting their fellow residents in dealing with the pandemic. At this juncture, they have also extended their support to the larger community in producing essential items like preparing masks, generating awareness, preparing and distributing cooking meals for the poor, and facilitating medical services. When others were restricted and kept themselves inside the four walls maintaining physical distance, these community groups came out from the four walls as COVID warriors fighting against the disease with selfprecaution. Because of their interdependence and interpersonal cooperation developed a circle of concern and provided a proactive focus on the pandemic.

However, social immunity has played an instinctive role among the community groups and boosted their collective energy for fighting against this crisis. Since years back, when women emerged as Self-Help Group (S.H.G.), nobody imagined our women would come up as a force to challenge the emergency in the future. Their involvement has become an example before the government machinery dealing with the crisis and has set a community task force model with their interdependence. When the world was struggling, and our machinery started showing its inefficacy to fulfill the basic survival needs of the citizens in supplying foods items, masks, sanitary items and making strategies for physical assistance, etc. S.H.G.s have emerged as COVID-19 solid warriors. They have proved that no great thing is possible in isolation. Instead, one can achieve it through exhibiting collective responsibility. Therefore, interdependence is the critical element that instinctively provides a robust social immunity to all to be proactive at the time of emergency. It offers extraordinary energy in an unusual situation and makes us realize how we all are interdependent in strengthening our social immunity.

\section{c. Social Immunity Initiatives among Health Care Providers}

Health Care Providers are the key agent in managing infections and controlling the spread of coronavirus. We have experienced that health care providers have a vital role in taking various social immunity initiatives during the disaster. Along with scientific management, they have established collaboration with other actors to control and manage the disease's preventive and curative aspects. We have seen ASHA and other health workers' teams visiting door to door to spread awareness for prevention, testing of infections, and motivating vaccinations. According to the WHO Director-General, Dr. Tedros Adhanom Ghebreyesus, "The COVID-19 pandemic has reminded all of us of the vital role of health workers to play to relieve suffering and save lives " (WHO,17 September 2020).

\section{Pandemic Confusion and Role of Social Immunity Framework}

The COVID-19 emerges as a global challenge with many misconceptions, distortion, and uncertainty, which has produced a lot of psycho-social and economic burden among the people for their basic survival. It has created an exploitative environment where "people have unfortunately found themselves overwhelmed with news containing fake reports and misinformation, which can be complicated to digest for those without the proper skills (Tagliabue, F. et al., 2020). The people immensely felt the need for social immunity and interdependence during the pandemic.

After analyzing the evidence and experiences, the authors have proposed a Social Immunity Framework to discuss the crucial elements contributing to Social immunity. Here, the authors wish to highlight that the dimensions in the framework are highly responsible for increasing or decreasing socio-biological immunity, sociopsychological tolerance, and disease avoidance.

The framework holistically provides an integrated approach to study the discussed phenomena and delivers a fair understanding of the social immunity in dealing with the dynamics of the crisis from a broader perspective. 
Fig No-1: Social Immunity (S.I.) Framework

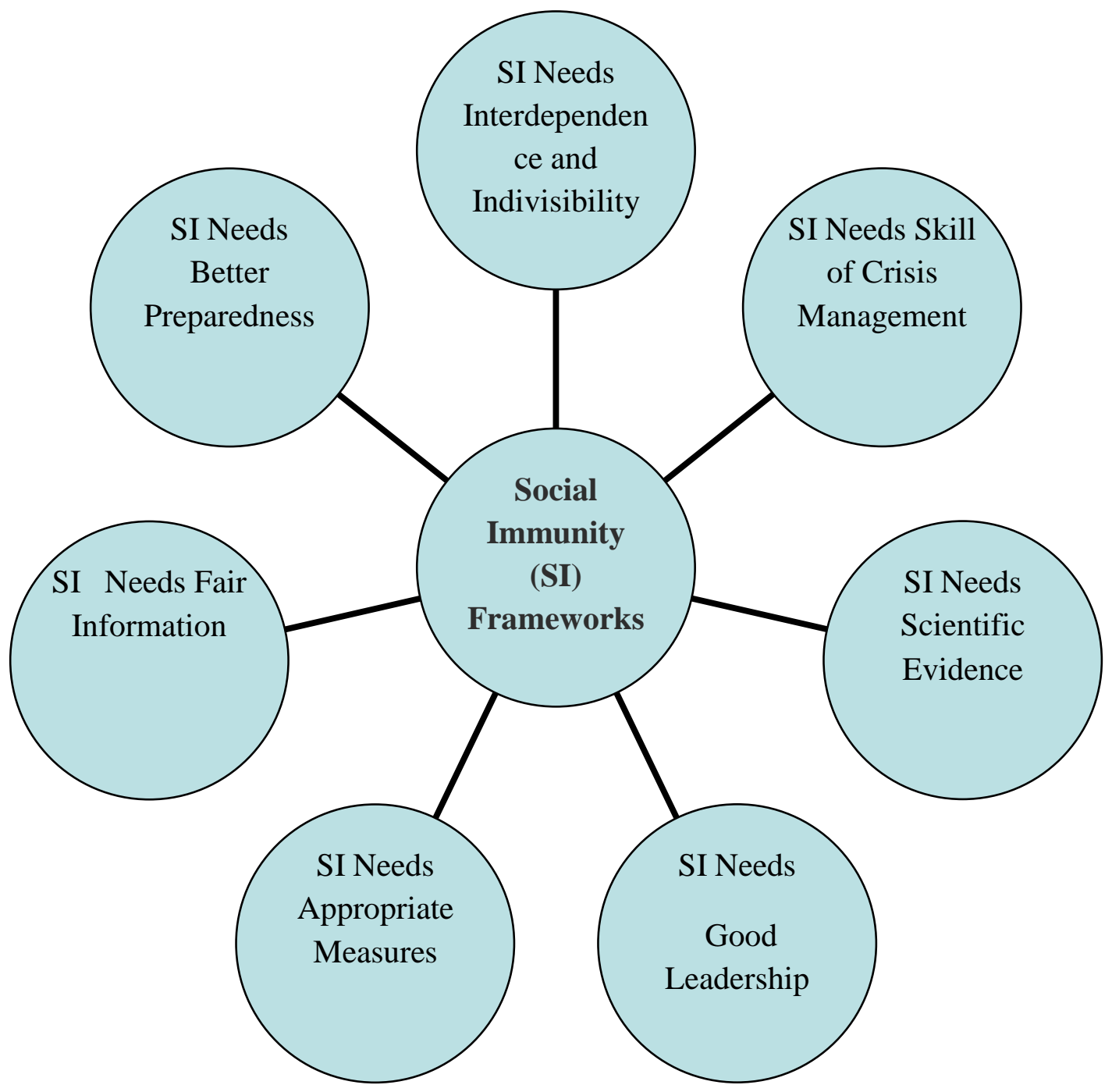

\section{i. Social Immunity Needs Fair Information}

Adequate information has a significant role in strengthening our social and individual immunity. It is found that "fake news and misinformation about COVID-19 have proliferated widely on social media, with potentially dangerous consequences" (Frenkel, S. et al., 2020). It is seen that adequate information influences entire human society in adopting and accepting new lifestyles with considering many new, confusing, and technical terms about the outbreak. It plays a dynamic role in influencing human behaviors and the social environment, which is irresponsible and jeopardizes the entire human race for a healthily living. Therefore, information and communication have a significant role in affecting our social immunity and strengthening our interdependence. The Director-General of the WHO, Mr. Tedros
Adhanom Ghebreyesus, in mid-February 2020 said that "we're not just fighting an epidemic; we're fighting an infodemic." Mentioning to fake news that "spreads faster and more easily than this virus." "WHO explains that infodemics are an excessive amount of information about a problem, making it difficult to identify a solution. They can spread misinformation, disinformation, and rumors throughout a health emergency. Infodemics can hinder an effective public health response and create confusion and distrust among people." WHO, (2020).

iii. Social Immunity Needs Scientific Evidence Evidence-based practice plays a decisive role and influences people's acceptability and adaptability. This evidence-based practice offers a rational model to the practitioners. It creates ample opportunities for the patients and health seekers to accept and adopt 
the particular practice model without hesitation, ultimately strengthening our social immunity. During a crisis like COVID-19, boosting social immunity poses many challenges. The virus spread worldwide and left people with uncertainty and ambiguity. Thus, the need for scientific evidence at the right time is significantly essential to develop social immunity to address the pandemic situation. During the pandemic, it is also seen that the huge incidence in mass media of doctors who expressed their opinions, sometimes not supported by scientific evidence, could be interpreted as a desire to appear rather than the need to provide the correct indications. The threatening tone of some experts has caused, in some cases, a rush to purchase personal protective equipment (P.P.E.) and alcoholic detergents; this fact partially contributed to the lack of P.P.E. in the clinical sector and a disproportionate increase in the prices of these products (Tagliabue, F. et al., 2020).

\section{iv. $\quad$ Social Immunity Needs Skill of Crisis Management}

Crisis management skills are one of the core areas determining control over the situation. Crisis management needs multidisciplinary support, and all these are interdependent. The essence of interdependence which is the core of social immunity, is heavily felt during crises. During COVID-19, it is experienced that behavioral aspects are primarily responsible for the high spread of the infection. The behavioral immune system (BIS) is thought to have evolved as the first line of defense against such ailments. It acts by minimizing the contact of yet uninfected hosts with potential pathogens (Shakhar, K., 2019). Therefore, appropriate and frequent hand washing, maintaining physical distancing, and using masks are essential for COVID-19 management. At the same time, it was the standard protocol by the health department. Social mapping, contact tracing, and quarantine emerged from the scientific shreds of evidence regarding the best defense mechanism and possible intervention for gaining social immunity. Vaccine intervention and its distribution are the key areas that need extraordinary focus, and "Segregation of sick individuals, disposal of the dead, quality assessment of food and waterand aggregation of immune individuals can protect non-immune members from disease" (Babayan, S. A \& Schneider, D.S., 2012).

\section{Social Immunity Needs Interdependence and Indivisibility}

It is observed that the importance of interdependence and indivisibility are instrumental for supportiveness. It became a survival strategy, giving their collective effort for protection and survival. Interdependence plays a pivotal role in mounting the social immune system to prevent the increased risk of disease transmission because of the group living.

In other words, indivisibility implies the quality of the commitment or agreement among the group members, and it has a more excellent social function. It creates a moral responsibility towards the protection of others' natural Rights. "Natural rights are rights granted to all people by nature or God that cannot be deprived of or controlled by any government or individual. Natural rights are often said to be granted to people by "natural law" (Longley. R., 2019). Even during the crisis, every individual has an equal right to protect their life and property. During the Pandemic importance of natural rights have great relevance to legal rights, and during the pandemic, the natural rights are phenomenal. Natural Rights insists that people react naturally, which triggers social immunity and interdependence to work together. Therefore, indivisibility is the natural condition that boots the social immunity and arouses interdependence in a more significant way, leading to providing a protective circle to each member from the unseen elements and creating a self-awareness regarding own degree of reactivity within the group.

On the other side, during the COVID-19 pandemic, it is also seen that pandemic confusion created troublesome behavior among the people in various places due to their loss of interdependency. They lost their trust and cooperation to the health care providers working as COVID warriors. Due to their troublesome behavior and irresponsible attitude, people lost their social immunity, for which the situation of COVID-19 became worse in various places.

\section{vi. Social Immunity Needs Better Preparedness}

"In an increasingly dangerous and uncertain world, preparedness, at all levels, for a range of threats is a key aspect of effective emergency management and public reassurance. Preparedness is a amalgamation of structural and non-structural measures designed to reduce known risks but also to ensure effective responses to a range of threats" (O'Brien, G., 2006). Therefore, social immunity needs better preparedness before spreading any disease, and it could be possible when people get appropriate information, training, and awareness. It requires integrational details on the nature of the disease, the inherent risk, and people's vulnerability through any participatory technique in advance to control the condition and minimize the causalities. During COVID-19, it is learned that basic preparedness of life-saving skills is highly required to protect the family and society. However, it requires a multidisciplinary approach to make strategies for better preparedness to combat the disease. It is experienced that "The complexity of the psychological, social, and economic interrelations of this new source of stress cannot be appropriately understood by scientific reductionism and specialised thinking only. It needs to 
be considered how the current pandemic links to questions of ecological sustainability and resilience" (Zabaniotou, A.,2020). Therefore, before taking any preparedness measures to strengthen social immunity, it is necessary to consider the dialogue of the multidisciplinary interdependence approach for handling the pandemic crisis.

\section{vii. Social Immunity Needs Appropriate Measures}

Appropriate measures are the decisive factors of any crisis. It is said that prevention is better than cure. Thus, it requires a crisis response plan before triggering. But COVD-19 was the exceptional one, and it precipitated an international crisis within a brief span. At the pandemic's beginning, nobody knew what to do and what not to do to address the situation. Before understanding its magnitude, it created massive devastation beyond the human race's imagination. Unlike other countries, India has taken some proactive measures to curb the situation, looking into the said emergencies. These were sealing of international borders, suspending air roots of international and domestic, screenings and compulsorily quarantining incoming travelers, calling of Janata curfew, suspending road and railway operations, adopting lockdown and short down measures, lighting candles and lamps, providing accurate information, etc. People are called to challenge the crisis by mapping and tracking measures, issuing an advisory for distancing, regular hand washing, using the mask, and using of Arogys Setu app. Our government has also announced various financial packages from time to time during the COVID-19 pandemic. It has also issued an order for three months E.M.I. moratorium from banks and financial institutions, direct benefit transfer, creating work from home opportunities, suspended of school and colleges, called for scientific innovations, taken national and global initiatives aimed at working with corona vaccine manufacturers innovations, called for start-up initiatives, technological initiatives for managing multiple problems, taken initiatives for national and international dialogue for better management of the pandemic situation, and supplied hydroxychloroquine to the cross border, etc. are the critical measures for prevention and mitigation of COVID crisis. All these initiatives have boosted the social immunity to deal with the virus.

\section{viii. Social Immunity Needs Good Leadership}

The role of leadership in crisis management is significant. The leader is the commander of a crisis journey. Leadership is the direction towards achieving the common purpose. A good Leader must have genuine compassion, and he can connect the people motivate, and inspire others to arouse interdependence. A good leader is the real booster of social immunity. Therefore, a good leader must have patience, foresightedness, commitment, and work beyond the position, according to Maxwell (2021). "Leaders become great, not because of their power, but because of their ability to empower others. They use their position, relationships, and productivity to invest in their followers and develop them until those followers become leaders in their own right. The result is reproduction. Leaders reproduce themselves. Production may win games, but People Development wins the championship."

During COVID-19, it is observed that women played an influential leadership role in handling the pandemic situations at various levels than their counterparts. Some of the evidence from the different studies are incorporated from the national and global level in establishing the influential role of women during the pandemic, which is highly responsible for boosting women's empowerment and gaining social immunity. According to the World Bank Group Report (11 April, 2020), "Women Self Help Groups in India have risen to the extraordinary challenge of COVID-19 (Coronavirus) pandemic. They meet shortfalls in masks, sanitizers, and protective equipment, run community kitchens, fight misinformation, and even provide banking and financial solutions to far-flung communities. They have set up over 10,000 community kitchens across the country to feed stranded workers, the poor, and the vulnerable. According to a global assessment by Zenger and Folkman (2020), "Women were rated as more effective leaders before and during the crisis." At the same time, at the national level, women leadership played a crucial role in the global arena during the pandemic, and they played their responsibilities for the nation as Minister of Finance and Corporate Affairs, President of FICCI, Chief Economist of I.M.P., Chief Scientist of WHO, etc. in dealing with the crisis. They have excellently exhibited their capability to lead for a change. They have leadership immunity in making change and strengthening social immunity. In a nutshell, leadership immunity provides a protective environment to the group members to make themselves resilient in the crisis. Leadership matters a lot in strengthening social immunity within the group. It helps bring agility among the group members in taking collective responsibility for the overall benefit of all the members.

\section{CONCLUSION}

Social immunity is the intrinsic rider of all living beings to prevent ailments. It has a robust defense mechanism that insists group members maintain a harmonious relationship with each other and meet social obligations for collective benefit. Thus, we conclude that social immunity is something to be more discussed in managing the COVID-19 pandemic. The procedural mechanisms need to be adopted to assess possible risks and consequences of 
the dynamic phenomena of uncertainty aroused from the COVID-19. The preventive tool could help develop multiple levels of defense; therefore, we need to collectivize our responsibility to solidify our social immunity to fight against the pandemic. We need to reflect every component of the Social Immunity Framework in risk assessment and management during a crisis. We should work with a collective responsibility to develop collective consciousness to overcome this uncertainty. However, as a protection pillar, we need to strengthen social immunity to fight against the deadly virus, which is only possible through collective responsibility.

\section{REFERENCES}

1. Cote I. M. and Poulin R. (1995). Parasitism and group size in social animals: a metaanalysis. Behav. Ecol. 6 159-165. 10.1007/3540-52921-7_92 [CrossRef] [Google Scholar]

2. Cotter, S. C. and Kilner, R. M. (2010). Personal immunity versus social immunity? Behavioral Ecology, 21 (4). pp. 663-668. ISSN 1045-2249.) Oxford University Press for International Society for Behavioral Ecology.

3. Crèmer, S. and Sixt, M.(2009). Analogies in the evolution of individual and social immunity, Philos Trans R Soc B Biol Sci, 2009, vol. 364 (pg. 129-142)

4. Cremer, S. and Kutzer, M. A. M. (January 01, 2017). Social Immunity, Institute of Science and Technology Austria (IST Austria), Klosterneuburg, Austria

5. Cremer, S., Armitage, S. A. O., and SchmidHempel, P. (2007). Social immunity. Curr. Biol. 17, 693-702. DOI: 10.1016/j.cub.2007.06.008

6. Earn, D. J. D., He, D., Loeb, M. B., Fonseca, K., Lee, B. E., and Dushoff, J. (2012). Effects of school closure on incidence of pandemic influenza in Alberta, Canada. Ann. Intern. Med. 156, 173-181. doi: 10.7326/0003-4819-156-3201202070-00005

7. Seppälä, E. (Ph.D. 23 March, 2020). Social Connection Boosts Health, Even When You're Isolated.

8. Fèvre, E. M., Bronsvoort, B. M. D. C., Hamilton, K. A., and Cleaveland, S. (2006). Animal movements and the spread of infectious diseases. Trends Microbiol. 14, 125-131. doi: 10.1016/j.tim.2006.01.004

9. Fraser, C., Riley, S., Anderson, R. M., and Ferguson, N. M. (2004). Factors that make an infectious disease outbreak controllable. Proc. Natl. Acad. Sci. U.S.A. 101, 6146-6151. doi: 10.1073/pnas.0307506101

10. Frenkel, S., Alba, D. \& Zhong, R. Surge of virus misinformation stumps Facebook and Twitter. The New York Times https://www.nytimes.com/2020/03/08/technology/ coronavirus-misinformation-social-media.html (2020).
11. Geoffrey, R. and Swain (2016-17). How does economic and social disadvantage affect health? Vol. 33 (1), Fall/Winter

12. Hatchett, R. J., Mecher, C. E., and Lipsitch, M. (2007). Public health interventions and epidemic intensity during the 1918 influenza pandemic. Proc. Natl. Acad. Sci. U.S.A. 104, 7582-7587. doi: 10.1073/pnas.0610941104

13. https://worldhappiness.report/ed/2020/socialenvironments-for-world-happiness/ retrieved on 8.12.2020

14. https://www.un.org/development/desa/indigenous peoples/covid-19.html

15. Shakhar, K. (2019). The Inclusive Behavioral Immune System. Frontiers in Psychology, 10.

16. Kroeger-Mappes, J. ( 1994). The ethic of care vis-à-vis the ethic of rights: A problem for contemporary moral theory. Hypatia, 108-131.

17. Maxwell, J.C. (2021). 5 Levels Of Leadership: Proven Steps To Maximize Your Potential. S.L.: Center St.

18. McCallum, H., Barlow, N., and Hone, J. (2001). How should pathogen transmission be modelled? Trends Ecol. Evol. 16, 295-300. doi: 10.1016/S0169-5347(01) 02144-9

19. Meunier, J. (2015). Social immunity and the evolution of group living in insects. Philosophical Transactions: Biological Sciences, 370, 1669, 1-10.

20. Napier, A. D. (2013). A new sociobiology: Immunity, alterity, and the social repertoire. Cambridge Anthropology, 31, 2, 20 43.

21. O'Brien, G. (2006). UK EMERGENCY PREPAREDNESS: A STEP IN THE RIGHT DIRECTION?. Journal of International Affairs, 59, 2, 63-85.

22. Robert Longley. Updated 07 July, 2019, https://www.thoughtco.com/what-are-naturalrights

23. Shultz, S., Opie, C., and Atkinson, Q. D. (2011). Stepwise evolution of stable sociality in primates. Nature 479, 219-222. doi: 10.1038/nature10601

24. Simon, A., Babayan, \& David S Schneider. (2012). Immunity in society: diverse solutions to common problems. Plos Biology, 10, 4.)

25. Tagliabue, F., Galassi, L., \& Mariani, P. (2020). The "Pandemic" of Disinformation in COVID19. SnComprehensiveClinical Medicine, 2020, 13.

26. Tognotti, E. (2013). Lessons from the history of quarantine, from plague to influenza A. Emerg. Infect. Dis. 19, 254-259. doi: 10.3201/eid1902.120312

27. U.N. tackles' infodemic' of misinformation and cybercrime in covid-19 crisis https://www.un.org/en/un-coronaviruscommunications-team/un-tackling\%e2\%80\%98infodemic\%e2\%80\%99misinformation-and-cybercrime-covid-19

28. WHO Coronavirus (COVID-19) Dashboard,(14 January 2022),

Availableat:https://covid19.who.int/

29. Wilson-Rich, N., Spivak, M., Fefferman, N. H., and Starks, P. T. (2009). Genetic, individual, and 
group facilitation of disease resistance in insect societies, Annu Rev Entomol, vol. 54 (pg. 405423)

30. World Bank Group. (April 11, 2020). In India, women's self-help groups combat the COVID119(Coronavirus) pandemic. Available athttps://www.worldbank.org/en/news/feature/20 20/04/11/women-self-help-groups-combatcovid19-coronavirus-pandemic-india

31. World Health Organization(17 September 2020). Keep health workers safe to keep patients safe: WHO, available at:

https://www.who.int/news/item/17-09-2020-keephealth-workers-safe-to-keep-patients-safe-who.

32. Zabaniotou, A. (2020). A systemic approach to resilience and ecological sustainability during the COVID-19 pandemic: Human, societal, and ecological health as a system-wide emergent property in the Anthropocene. Global Transitions, 2, 116-126.

33. Zenger, J. and Folkman, J. (2020). Research: Women Are Better Leaders During a Crisis, Harvard Business Review, available at: https://hbr.org/2020/12/research-women-arebetter-leaders-during-a-crisis 